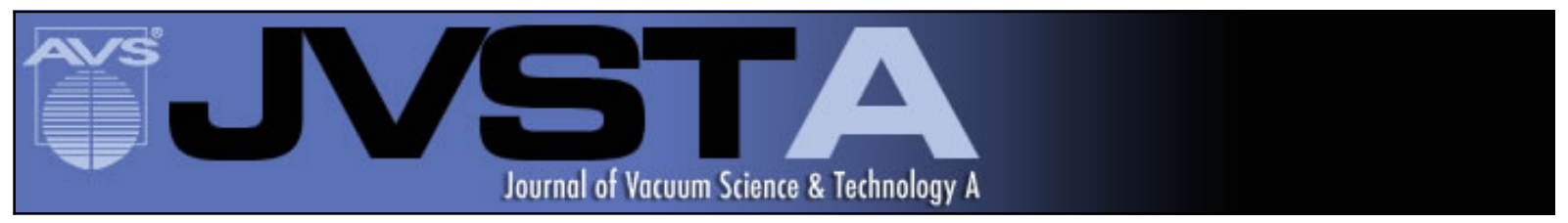

\title{
Processing of $\mathrm{PbTiO} 3$ thin films. III. Effects of ion bombardment
}

Chen C. Li and Seshu B. Desu

Citation: Journal of Vacuum Science \& Technology A 14, 13 (1996); doi: 10.1116/1.579910

View online: http://dx.doi.org/10.1116/1.579910

View Table of Contents: http://scitation.aip.org/content/avs/journal/jvsta/14/1 ?ver=pdfcov

Published by the AVS: Science \& Technology of Materials, Interfaces, and Processing

\section{Articles you may be interested in}

Xray photoelectron spectroscopy study on composition and structure of solgel derived $\mathrm{PbTiO} 3$ thin films J. Appl. Phys. 80, 202 (1996); 10.1063/1.362805

caxis oriented ferroelectric thin films of $\mathrm{PbTiO} 3$ on $\mathrm{Si}$ by pulsed laser ablation

Appl. Phys. Lett. 68, 1582 (1996); 10.1063/1.116687

Processing of $\mathrm{PbTiO} 3$ thin films. I. In situ investigation of formation kinetics

J. Vac. Sci. Technol. A 14, 1 (1996); 10.1116/1.579919

Processing of $\mathrm{PbTiO} 3$ thin films. II. In situ investigation of stress relaxation

J. Vac. Sci. Technol. A 14, 7 (1996); 10.1116/1.579883

Difference Raman spectra of $\mathrm{PbTiO} 3$ thin films grown by metalorganic chemical vapor deposition Appl. Phys. Lett. 62, 349 (1993); 10.1063/1.108954
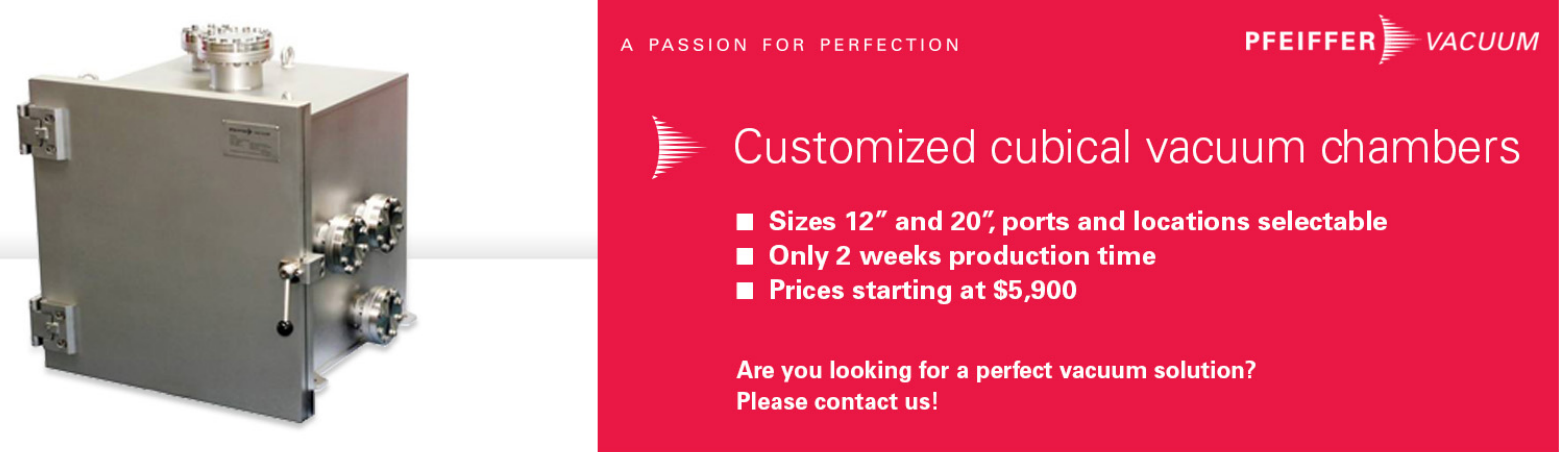


\title{
Processing of $\mathrm{PbTiO}_{3}$ thin films. III. Effects of ion bombardment
}

\author{
Chen C. Li and Seshu B. Desu ${ }^{\text {a) }}$ \\ Department of Materials Science and Engineering, Virginia Polytechnic Institute and State University, \\ Blacksburg, Virginia 24061
}

(Received 28 July 1994; accepted 7 October 1995)

\begin{abstract}
The effects of ion bombardment on multicomponent oxides, such as $\mathrm{PbTiO}_{3}$, and multilayer systems have been extensively studied by an in situ stress measurement technique. Energetic ion bombardment was found to accelerate $\mathrm{PbTiO}_{3}$ formation. Both the annealing temperature and the time needed for completion of the reaction were reduced. The apparent activation energy responsible for stress relaxation was found to be $310 \mathrm{~kJ} / \mathrm{mole}$ for ion-assisted deposition (IAD) films, which is $120 \mathrm{~kJ} / \mathrm{mole}$ higher than that for non-IAD films. This was attributed to stress reduction in $\mathrm{PbTiO}_{3}$ thin films resulting from ion bombardment. In addition, effects of ion bombardment on the stress of as-deposited multilayers, on the stress development in multilayers during annealing, and on the structure-property-processing interrelationships were also investigated. (C) 1996 American Vacuum Society.
\end{abstract}

\section{INTRODUCTION}

Ion-assisted deposition (IAD) is a process, as shown in Fig. 1, in which a growing film produced from an evaporation source (usually an electron beam) is bombarded by an ion beam produced by a low-energy $(50 \mathrm{eV}-1 \mathrm{keV})$ ion source. IAD offers independent control over fluxes of ions and evaporated atoms, ion energy, nature of ion species and their charge state, incident direction (and divergence), background pressure, composition and, if necessary, the substrate temperature. For this low-energy range in IAD, four most important physical processes, including desorption or sputtering of impurities from the substrate surface by ion impact, penetration and entrapment of the coating and support gas in the growing film, sputtering of the substrate and eventually the coating with increasing film growth, and the generation of defects in the substrate and growing film, have been identified. ${ }^{1}$ In addition, the energetic bombardment can also enhance the migration of the deposited atoms along the substrate surface. Furthermore, ions of low energies may influence film nucleation and growth and enhance chemical reactivity.

Effects of ion bombardment on simple (one or two element systems) and single layer thin film systems have been reviewed and are well documented. ${ }^{2}$ Examples of these effects include grain size, ${ }^{3}$ preferred crystalline orientation, ${ }^{4}$ increased (or decreased) packing density, ${ }^{5}$ lattice expansion and contraction, ${ }^{6}$ surface topological effects, ${ }^{7}$ enhanced surface or bulk diffusion, ${ }^{8}$ nucleation density ${ }^{9}$ in the early stages of film growth, and other related effects such as film stoichiometry ${ }^{9}$ and the modification of thin film stresses. ${ }^{10}$ However, ion beam effects in multicomponent oxides and/or multilayers have not been studied and this was the major focus of this study.

Using IAD to deposit multilayers, several phenomena such as entrapment of the incident ions, e.g., argon, in the multilayer, densification of the individual layers, implantation and intermixing between film and substrate and between

a) Author to whom correspondence should be addressed. film and film, and creation of activated centers for nucleus formation of the $\mathrm{PbTiO}_{3}$ phase, can be expected. Accordingly, the multilayers are never in true thermodynamic equilibrium, therefore, kinetics of film growth can be altered and in turn can dramatically affect the properties of the growing film.

Recently, we have successfully formed multicomponent oxides, such as $\mathrm{PbTiO}_{3}$ thin films, using the $\mathrm{PbO} / \mathrm{TiO}_{2}$ multilayer approach. ${ }^{11}$ The formation of the $\mathrm{PbTiO}_{3}$ phase has been studied using an in situ method by monitoring changes of stresses in the multilayers. ${ }^{12}$ The formation kinetics and stress relaxation of the $\mathrm{PbTiO}_{3}$ films have been documented. ${ }^{12,13}$ In this work, we studied the effects of ion bombardment on the formation kinetics and stress relaxation of $\mathrm{PbTiO}_{3}$ films. In addition, the effects of ion bombardment on the initial stress of as-deposited multilayers, the stress development of the multilayers during annealing, and the structure-property-processing relationships are also discussed.

\section{EXPERIMENTAL PROCEDURE}

The experimental arrangement for the deposition system was discussed in detail in a previous study. ${ }^{12,13}$ A conventional cryopumped electron beam evaporation system was modified by the addition of a 3-cm-broad beam Kaufman ion gun with dual defocused graphite grid optics. The gun was used to provide a beam of low-energy $(30-1500 \mathrm{eV}) \mathrm{Ar}^{+}$ ions incident on the substrate surface at an angle of $30^{\circ}$ from substrate normal. Two-in.-sapphire substrates with [1-102] direction were placed $34 \mathrm{~cm}$ above the electron beam evaporation source. The substrates were cleaned by a series of organic solutions and de-ionized water followed by drying in $\mathrm{N}_{2}$ gas. Prior to deposition, the substrates were further cleaned by low-energy ion bombardment for $2 \mathrm{~min}$. High purity, vapor deposition grade oxides $(99.999 \% \mathrm{PbO}$ and 99.995\% $\mathrm{TiO}$ ) were used as the evaporation sources. The oxides were conditioned prior to evaporation to prevent them from splattering. 


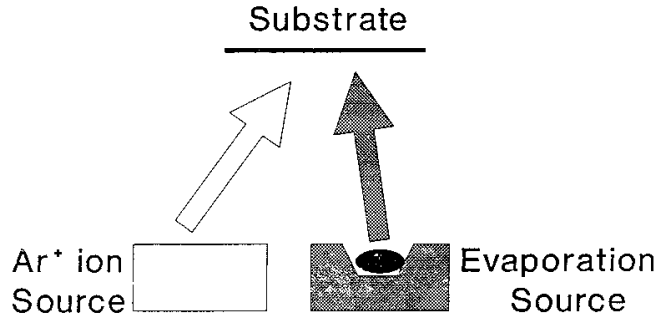

FIG. 1. Schematic of the IAD deposition process.

Prior to deposition, the system was pumped down to $4 \times 10^{-7}$ Torr, then rising to $\sim 10^{-6}$ Torr for conventional evaporation operation. The chamber pressure was brought up to $8 \times 10^{-5}$ Torr by introducing high purity $(99.999 \%)$ Ar gas for ion-assisted deposition operation. All deposition was performed at ambient substrate temperature. The deposition rates of both oxides were kept constant at $0.3 \mathrm{~nm} / \mathrm{s}$ for $\mathrm{TiO}$ and $0.5 \mathrm{~nm} / \mathrm{s}$ for $\mathrm{PbO}$, for which the molecules of both oxides could have the same arrival rate onto the substrate. Total film thickness was kept constant at $300 \mathrm{~nm}, 100 \mathrm{~nm}$ for the $\mathrm{TiO}$ layer and $200 \mathrm{~nm}$ for the $\mathrm{PbO}$ layer, in which the loss of $\mathrm{PbO}$ layer was taken into account. The deposition scheme is shown in Fig. 2, in which the number of ions and atoms arriving on the substrate are plotted as functions of the processing time. The substrate was subjected to sputter cleaning for $2 \mathrm{~min}$ by the bombardment of $600 \mathrm{eV}$ ion beams. Then the beam energy was turned down to a designated energy and deposition started. The oxide multilayer was deposited under a concurrent bombardment of $\mathrm{Ar}^{+}$ion irradiation with several different ion beam energies $(100,200$, and $300 \mathrm{eV})$ and an ion flux density ranging from 30 to $160 \mu \mathrm{A} / \mathrm{cm}^{2}$.

Film stress measurements as functions of temperature $\left(550-600^{\circ} \mathrm{C}\right)$ and time $(120-240 \mathrm{~min})$ were performed for the $\mathrm{PbO} / \mathrm{TiO}$ oxide multilayers. The heating rate was $5{ }^{\circ} \mathrm{C} /$ $\min$. The value of film stress was characterized by the curvature method. The in situ stress measurement technique was developed and was thoroughly described in Part II. ${ }^{13}$ Selected as-deposited films were also subjected to postdeposition annealing in a conventional box furnace using the same annealing profile. The development of the $\mathrm{PbTiO}_{3}$ phase and the texture in the films was identified by x-ray diffraction

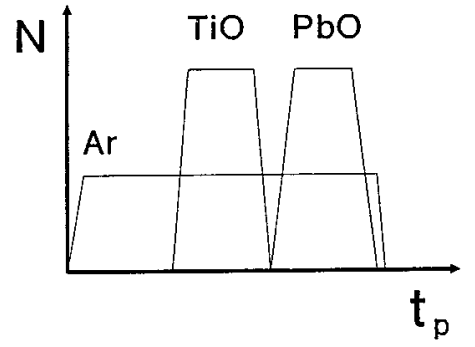

FIG. 2. Sequence of multilayer deposition. $N$ : number of ions and atoms arriving at the target; $t_{p}$ : process time.

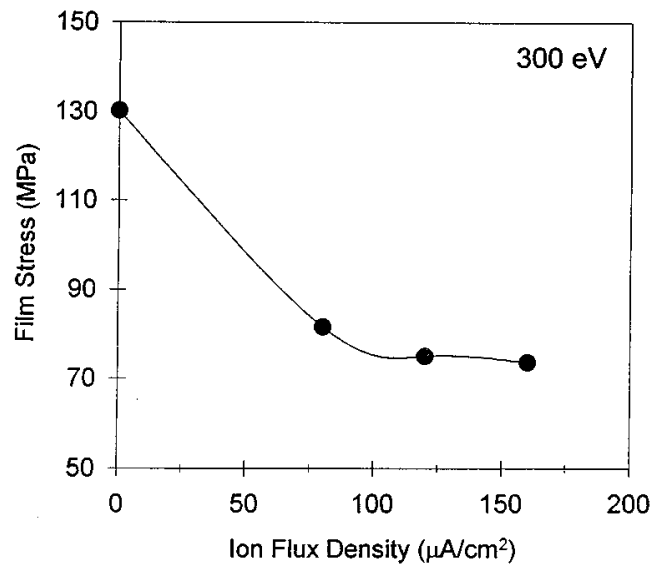

FIG. 3. Film stress of as-deposited multilayers as a function of ion flux density.

analysis. The evolution of the film morphology, such as grain size, was examined by scanning electron microscopy.

\section{RESULTS AND DISCUSSION}

In general, compressive stresses are found when a growing film is bombarded by atoms or ions with energies of tens or hundreds of $\mathrm{eV}$ by a mechanism known as "ion peening." ${ }^{10}$ The energetic ions or atoms are forced into previously unoccupied interstitial sites because of their high kinetic energy or as a result of impacting with other highvelocity particles, ${ }^{14}$ which leads to an expansion of the film outward from the substrate. However, the film is not free to expand in the plane of the film and, therefore, the entrapped atoms and/or ions cause macroscopic compressive stresses.

\section{A. Effect of ion bombardment on the stress of as-deposited multilayers}

Figure 3 shows the effect of ion bombardment on the stress of as-deposited $\mathrm{TiO} / \mathrm{PbO}$ multilayers as a function of ion flux density for an ion energy of $300 \mathrm{eV}$. Since the multilayer was prepared at ambient temperature, the observed film stress was the intrinsic stress. It was found that the intrinsic stress decreased with increasing ion flux density. In other words, compressive stress developed when the growing multilayer was bombarded by the energetic ions. The argon ions and depositing atoms were forced into previously unoccupied interstitial sites because of their high kinetic energy or as a result of impacting with other highvelocity particles. ${ }^{14}$ It is also likely that the generation of compressive stress was partially due to incorporation of the incident $\mathrm{Ar}^{+}$ions in the growing films.

The film stress in the as-deposited multilayer approached a constant value when the ion flux density was above 100 $\mu \mathrm{A} / \mathrm{cm}^{2}$. This implies that film stress cannot be changed further after the ion flux density reaches a certain critical value. Stress behavior similar to that shown in Fig. 3 has also been found in IAD-deposited chromium films. ${ }^{15}$ For chromium films, the critical ratio value indicated the condition at which 

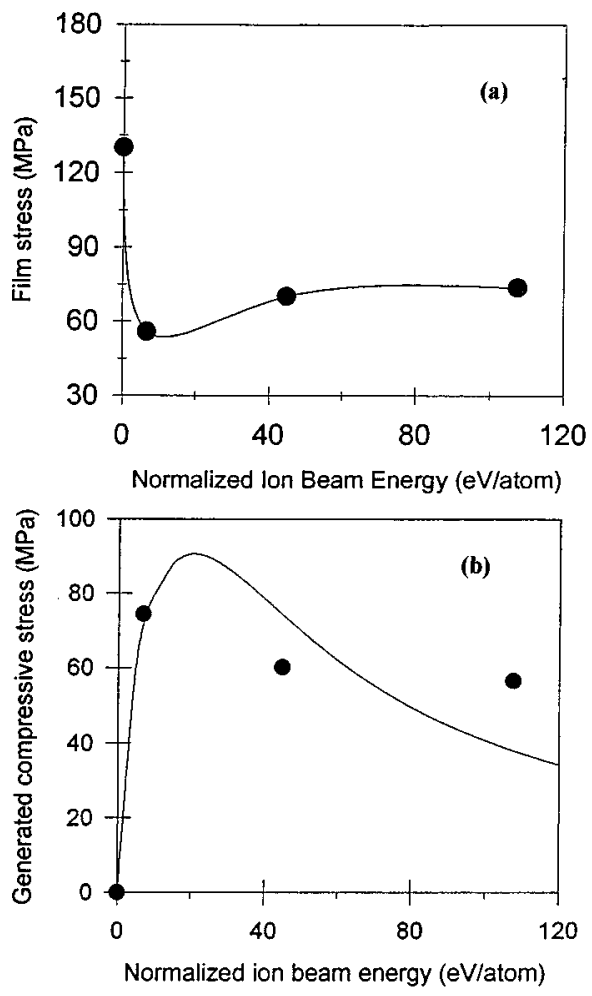

FIG. 4. Film stress of as-deposited multilayers as a function of normalized ion beam energy. (a) Film stress; (b) generated compressive stress.

film stress changed from tensile to compressive. However, compressive stress was never found in the as-deposited $\mathrm{TiO} /$ $\mathrm{PbO}$ multilayers in this study.

It is believed that changes in IAD thin films cannot be related only to ion flux density, but can also be related to ion energy. Figure 4(a) shows the effect of ion bombardment on film stress as a function of normalized ion beam energy in eV/atom, which is simply the product of the relative ion/ atom flux and the average ion energy. The normalized ion beam energy indicates the average kinetic energy carried by each individual deposited atom. The tensile stress of the asdeposited multilayers initially decreased, then later slightly increased as the normalized ion beam energy increased. The minimum was found at a normalized ion beam energy of approximately $6.6 \mathrm{eV}$. With increased normalized ion beam energy, the tensile stress increased slightly. Similar stress behavior [like that seen in Fig. 4(a)] has also been reported in IAD-deposited copper films on silicon substrates. ${ }^{16}$

To compare the stress of the IAD-deposited films with that of the evaporated films, the generated compressive film stress was plotted as a function of normalized ion beam energy, as shown in Fig. 4(b). The generated compressive stress showed a maximum at around $6.6 \mathrm{eV}$. Davis ${ }^{17}$ considered a steady state in which film stress formation by knock-on implantation of film atoms is balanced by thermal spike excited migration of implanted atoms, and also showed that film stress, $\sigma$, is proportional to

$$
\sigma \propto\left[E_{f} /\left(1-\nu_{f}\right)\right]\left[E^{1 / 2} /(M / I)+k E^{5 / 3}\right],
$$

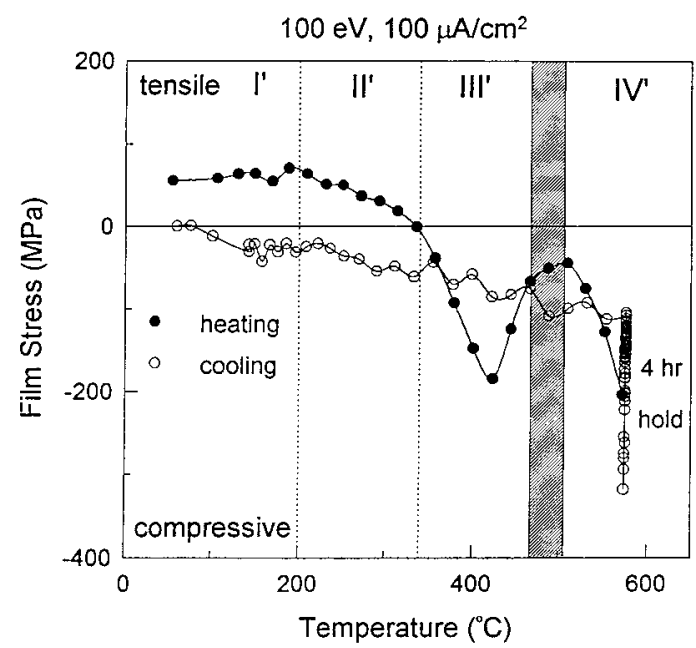

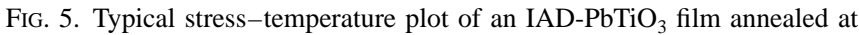
$575^{\circ} \mathrm{C}$ for $4 \mathrm{~h}$.

where $E$ is the ion energy, $M$ the net depositing flux, $I$ the ion flux, $\left[E_{f} /\left(1-\nu_{f}\right)\right]$ the biaxial modulus of the film, $k=0.016 \rho E_{0}^{-5 / 3}$ ( $\rho$ is a material-dependent parameter which is of order 1 and $E_{0}$ is the excitation energy of the film material).

Replacing $E$ by $E_{n}$, the normalized ion beam energy, the generated compressive stress, as shown in Fig. 4(b), can be curve fitted by the following equation:

$$
\sigma=\left[E_{f} /\left(1-\nu_{f}\right)\right]\left(c E_{n}^{1 / 2} / a+b E_{n}^{5 / 3}\right)
$$

where $a=(M / I)^{1 / 2}, b=k(M / I)^{7 / 6}$, and $c$ is a proportionality constant. Assuming $E_{0}=4 \mathrm{eV}$ and $r=1$ and by taking the average $I / M$ ratio to be 0.4 , the theoretical curve was obtained and plotted as shown in Fig. 4(b).

Although the experimental data were limited, a relatively good fit was obtained. The behavior was similar to that obtained previously in the literature. ${ }^{18}$ The initial rapid rise and later reduction in stress at larger normalized ion beam energies were modeled. Davis ${ }^{17}$ explained that this phenomenon is caused by a balance between the knock-on implantation and the thermal spike relaxation processes. At lower energy levels, the implantation process is predominant and the relaxation process is insignificant. Whereas, at higher energy levels, the generated compressive stress is partially relaxed by the thermal spikes. The extent of relaxation was found to be dependent upon the normalized ion beam energy level.

\section{B. Effect of ion bombardment on the stress development in multilayers}

Figure 5 depicts a typical stress-temperature plot for a $\mathrm{PbO} / \mathrm{TiO}$ multilayer (on a sapphire substrate) that was subjected to annealing in air at $575{ }^{\circ} \mathrm{C}$ for $4 \mathrm{~h}$ at a heating rate of $5{ }^{\circ} \mathrm{C} / \mathrm{min}$. This multilayer was deposited under a concurrent $\mathrm{Ar}^{+}$ion bombardment with an ion energy of $100 \mathrm{eV}$ and ion flux density of $100 \mu \mathrm{A} / \mathrm{cm}^{2}$. For a better understanding, Fig. 5 was divided into four regions. In this section, we describe the processes occurring during the heating stage. Film stress 
during cooling showed good linearity against temperature and therefore the thermal stresses could be readily obtained. From the slope of the cooling region in Fig. 5, thermal expansion coefficients of the $\mathrm{PbTiO}_{3}$ films could be derived. It was found that the thermal expansion coefficient of $\mathrm{PbTiO}_{3}$ films was dependent on processing parameters such as ion energy and ion flux density. These phenomena will be discussed later.

During heating, no significant change was observed in the film stress with increasing temperature (region $\mathrm{I}^{\prime}$ ) up to a temperature of $200{ }^{\circ} \mathrm{C}$. Above a temperature of $200{ }^{\circ} \mathrm{C}$, increased compressive stress started building up in the films as can be seen from region II' $^{\prime}$ in Fig. 5. The development of compressive stress was found to occur at a faster rate as the curve entered region $\mathrm{III}^{\prime}$ at around $340{ }^{\circ} \mathrm{C}$ and the stress value reached a minimum at around $420^{\circ} \mathrm{C}$. With a further increase in temperature, tensile stress started to build up in the films and reached a local maximum at around $500{ }^{\circ} \mathrm{C}$. The stress development in regions II' and III' could be attributed to further oxidation of both the oxide layers. The incorporation of oxygen into the multilayers from the atmosphere could result in increased film volume and thereby the generation of compressive stress. In region II', the buildup of compressive stress was found to be less than that in region III'. This could be attributed to compensation through the release of trapped argon atoms in the films. The process of releasing argon atoms (observed in region $\mathrm{II}^{\prime}$ ) was found to be complete at a temperature around $340{ }^{\circ} \mathrm{C}$. This value has been found to be close to $300{ }^{\circ} \mathrm{C}$ for tungsten films, ${ }^{19}$ although it could vary depending on the material. Accordingly, the increasing rate of compressive stress generation in region III' was accounted for mainly by the intake of oxygen atoms into the films. For regions III' and IV', the stresstemperature curve fell entirely into the compressive state. Compressive stress continued to develop in the films when the temperature was above $500{ }^{\circ} \mathrm{C}$ and reached a local minimum in the isothermal region following which tensile stress started building up once again. Region IV was attributed to the formation of the $\mathrm{PbTiO}_{3}$ phase in the film and to stress relaxation. The location of the boundary between regions III' and $\mathrm{IV}^{\prime}$ was uncertain because of the existence of the intermixed layer between the oxide layers. Therefore, the initial formation temperature of the $\mathrm{PbTiO}_{3}$ phase was uncertain in terms of the stress-temperature plot.

Compared to electron beam evaporation, the ion-assisted deposition process provides a much more complicated picture in multilayers. An oxide multilayer prepared by evaporation can result in a sharp interface between layers, as shown in Fig. 6 (left side), and oxygen deficiency in each layer if decomposition occurs. In the IAD process, with energetic particle bombardment during deposition, several phenomena could alter the nature of the multilayers: (1) sputtering and preferential sputtering which causes offstoichiometry, such as oxygen deficiency in the films; (2) recoil and ion implantation which can cause intermixing be-

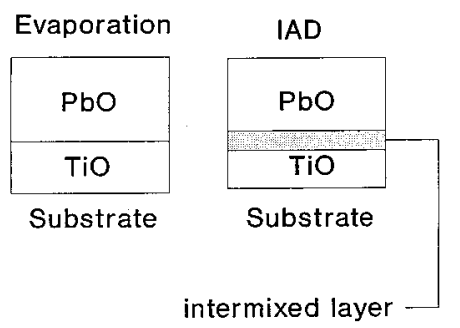

FIG. 6. Effect of ion bombardment on multilayer formation (see the text for details).

tween layers, as shown in Fig. 6 (right side); and (3) ion trapping which can result in the incorporation of impurity ions such as Ar in the films. In our case, we believe that the existence of the intermixed layer and thereby the uncertain boundary between regions III' $^{\prime}$ and IV' $^{\prime}$ were caused by the second phenomenon. For comparison, the data during heating stage were replotted with another plot $^{12}$ in which the multilayer was prepared without ion bombardment, as shown in Fig. 7. Figure 7 clearly displays the effect of ion bombardment on stress development in multilayers. Comparison of these plots clearly shows that region II occurs at higher temperatures in the case of non-IAD films (Fig. 7, upper panel) and that region II expanded towards lower temperature when the growing films were bombarded by energetic $\mathrm{Ar}^{+}$ions (Fig. 7, lower panel). The boundary between III' $^{\prime}$ and IV $^{\prime}$ in Fig. 7, lower panel, is not as well defined as that between II and III in Fig. 7, upper panel, because the thickness of the intermixed layer, which is believed to affect film stress as the temperature reaches a value close to $500{ }^{\circ} \mathrm{C}$, could not be accurately determined. The formation of the $\mathrm{PbTiO}_{3}$ layer might have occurred prior to $500{ }^{\circ} \mathrm{C}$.

The isothermal region in region IV $^{\prime}$ for several different annealing temperatures was replotted in Fig. 8. It is clear that in region IV' stress developments involve two kinetic processes, namely, $\mathrm{PbTiO}_{3}$ formation and stress relaxation. These two processes will be discussed later in this article.

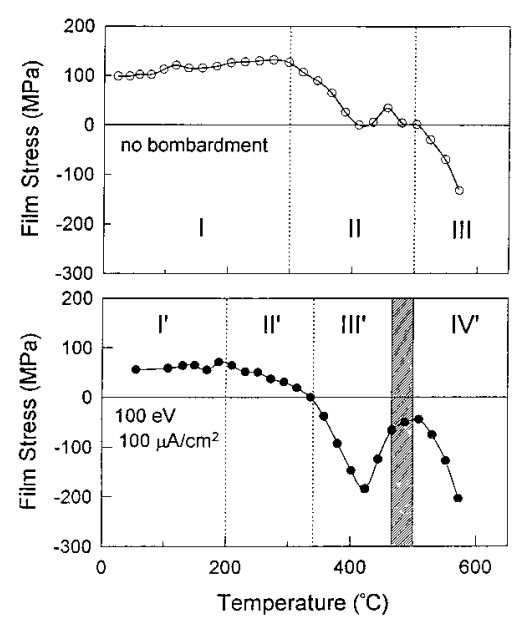

FIG. 7. Heating stage of the stress-temperature plots (see the text for details). 

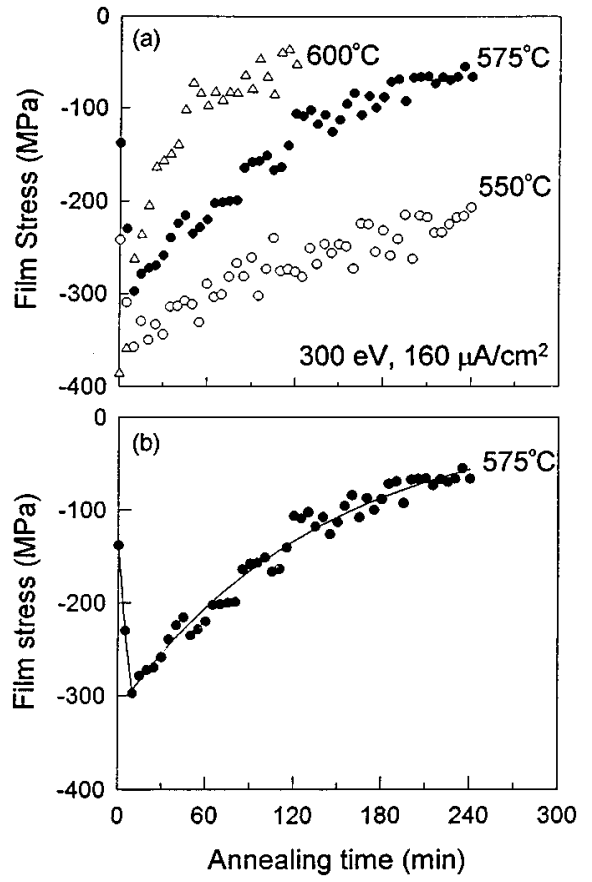

FIG. 8. (a) Typical stress-time plots for $\mathrm{PbTiO}_{3}$ films as a function of annealing temperature. (b) Stress-time plot for the films annealed at $575{ }^{\circ} \mathrm{C}$; note the minimum in the plot as the growth process is completed.

The development of compressive stress in the early stages of the stress-time plots (Fig. 8) was attributed to the growth of the $\mathrm{PbTiO}_{3}$ layer. ${ }^{12}$ During the growth process, absorption of vacancies from a free surface by the product layer may have caused compressive stress because of the "swelling" of the deposit. As the growth process reached completion, film stress reached an extreme as can be seen by the local minima in Fig. 8. These phenomena were verified in our previous study $^{12,13}$ and were also confirmed by $\mathrm{x}$-ray diffraction analysis in this work. After the completion of $\mathrm{PbTiO}_{3}$ formation, stress relaxation appeared to play the dominant role in stress development and also in the generation of tensile stress.

In the past, the in situ stress measurement technique has been successfully adopted to characterize the kinetics of compound formation in multilayers when the reaction is relatively fast. ${ }^{12}$ In the IAD-deposited thin film systems, the reaction between layers was found to be faster and complete at lower temperatures. For instance, using the same heating rate, $5{ }^{\circ} \mathrm{C} / \mathrm{min}, \mathrm{PbTiO}_{3}$ formation was complete before the temperature reached $600{ }^{\circ} \mathrm{C}$ for IAD films, whereas the equivalent condition was $600^{\circ} \mathrm{C}$ and 20 min for non-IAD films. ${ }^{12}$ For an annealing temperature of $550{ }^{\circ} \mathrm{C}$, the reaction was complete in $\sim 20 \mathrm{~min}$ for IAD films in contrast to approximately $100 \mathrm{~min}$ for non-IAD films. ${ }^{12}$ Both the kinetics and activation energy responsible for the reaction are very difficult to determine because of the uncertain boundary between regions III' and IV $^{\prime}$ due to the existence of the intermixed layer. This boundary is of great importance in defining the initial stress value, $\sigma_{i}$, which indicates the start of reaction during annealing. Besides, the thickness of the inter-

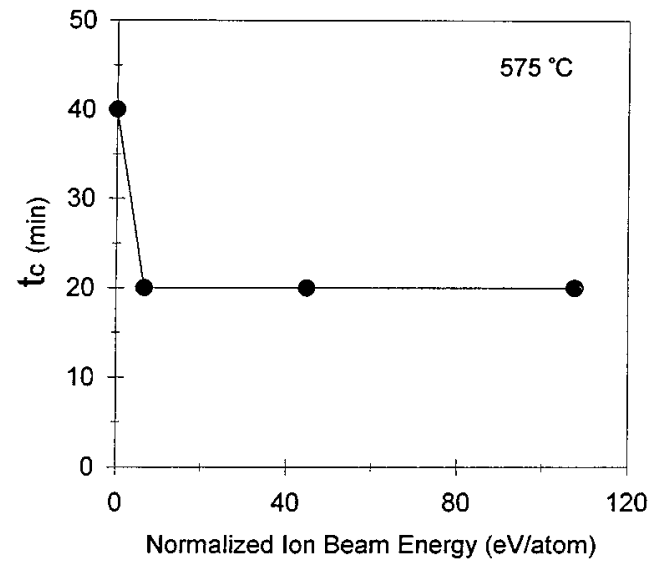

FIG. 9. $t_{c}$ as a function of normalized ion beam energy.

mixed layer cannot only shift the location of $\sigma_{i}$, but can also change the value of $\sigma_{i}$.

Since the kinetics of reaction were difficult to investigate in IAD films, the effect of ion bombardment on $\mathrm{PbTiO}_{3}$ formation was studied using other parameters such as $t_{c}$, the time needed to complete $\mathrm{PbTiO}_{3}$ formation at a given temperature. Figure 9 shows the effect of normalized ion beam energy, eV/atom, on $t_{c}$, for an annealing temperature $575^{\circ} \mathrm{C}$. $t_{c}$ dropped from $40 \mathrm{~min}$ for non-IAD films to $20 \mathrm{~min}$ for IAD films under a normalized ion energy of $6.6 \mathrm{eV}$. It was also found that $t_{c}$ remained at $20 \mathrm{~min}$ as the normalized ion beam energy increased. The value of $6.6 \mathrm{eV}$ is of the same order as the bond energy of average materials. This result therefore suggested that the formation kinetics of $\mathrm{PbTiO}_{3}$ formation was altered by the bombardment of energetic $\mathrm{Ar}^{+}$ions. The transfer of energy from ions to atoms was sufficient to overcome the activation energy of the reaction. The formation of the $\mathrm{PbTiO}_{3}$ phase was also accelerated by the ion bombardment. However, the reaction could not be promoted further by ion bombardment using higher energies. The excess energy was expected to transform into thermal energy and be absorbed by the films and the substrate.

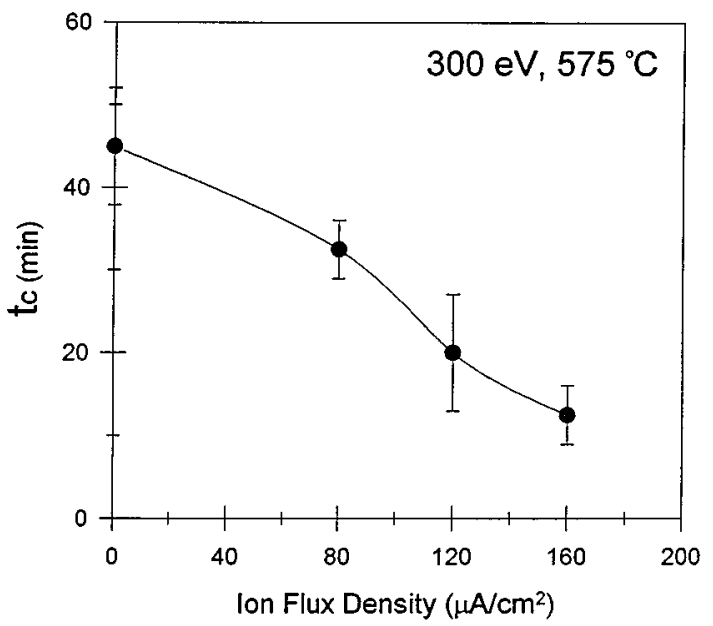

FIG. 10. $t_{c}$ as a function of ion flux density. 


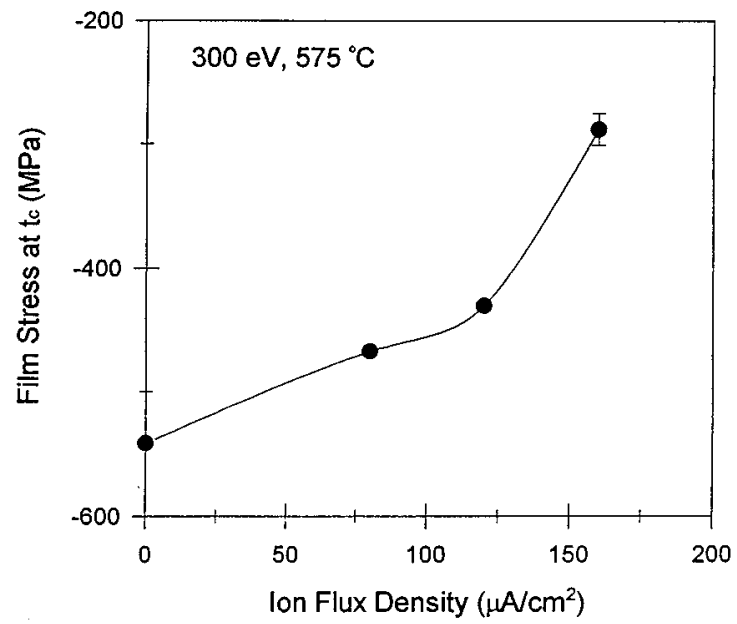

FIG. 11. Film stress at $t_{c}$ as a function of ion flux density.

Figure 10 depicts the effect of ion bombardment on $t_{c}$ as a function of ion flux density for $300 \mathrm{eV}$ ion beams. The error bars in Fig. 10 indicate the time interval of stress measurement. It was found that $t_{c}$ decreased as ion flux density increased. This phenomenon could be attributed to the increase in nucleation density at the intermixed layer between the $\mathrm{PbO}$ and $\mathrm{TiO}_{2}$ layers. In general, the effect of ion irradiation is to create activation sites that stimulate nucleation. ${ }^{20}$ It was found ${ }^{21,22}$ that increasing the ion flux density could increase the nucleation density during film growth. Accordingly, the kinetics of $\mathrm{PbTiO}_{3}$ formation could be aided by the increase in nucleation sites at the intermixed layers caused by increasing ion flux density. Figure 11 shows the stress of $\mathrm{PbTiO}_{3}$ films upon formation at $575^{\circ} \mathrm{C}$. It was found that the compressive stress in $\mathrm{PbTiO}_{3}$ films was reduced upon formation due to ion bombardment and decreased with increasing ion flux density at $300 \mathrm{eV}$.

As far as stress relaxation is concerned, we have shown in our previous study ${ }^{12}$ that the stress relaxation behavior of $\mathrm{PbTiO}_{3}$ thin films (deposited without ion bombardment) can successfully be described by a viscous flow model, obeying an exponential relationship with time, i.e.,

$$
\sigma=\sigma_{0} \exp (-E t / \eta)
$$

where $E$ and $\eta$ are the Young's modulus and viscosity of the films, respectively, and $\sigma_{0}$ is the pre-exponential factor.

Using the above relation, we studied the stress relaxation behavior of the $\mathrm{PbTiO}_{3}$ films deposited with $\mathrm{Ar}^{+}$ion bombardment at an energy of $300 \mathrm{eV}$ and a flux density of 160 $\mu \mathrm{A} / \mathrm{cm}^{2}$. The absolute value of the data in the region of relaxation shown in Fig. 8 was replotted in a semilog scale of stress against time, as shown in Fig. 12. All the data (except that at $600{ }^{\circ} \mathrm{C}$ ) showed very good linearity. The deviation of the data from the straight line at $600{ }^{\circ} \mathrm{C}$ could have been caused by a change in the relaxation mechanism. From the slopes of the straight lines in Fig. 12, the viscosity, $\eta$, was obtained (as shown in Fig. 13) by taking the Young's modulus of $\mathrm{PbTiO}_{3}$ films as $13.1 \times 10^{11} \mathrm{dyn} / \mathrm{cm}^{2}{ }^{23}$ The values of viscosity were found to obey an Arrhenius relationship:

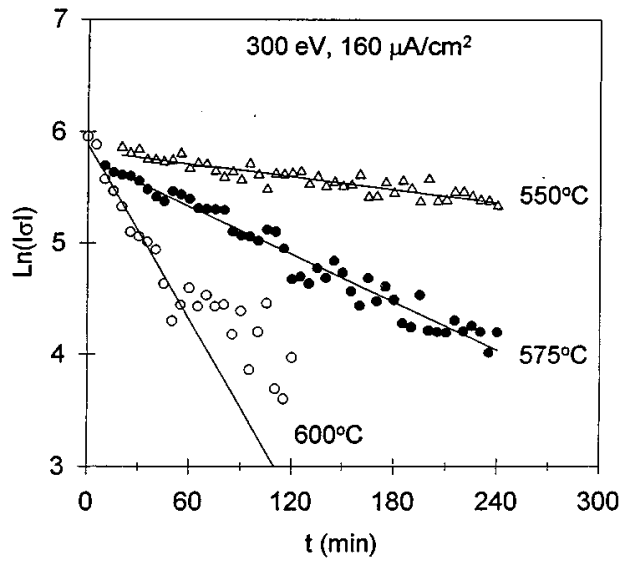

FIG. 12. $\ln (|\sigma|)$ as a function of time.

$$
\eta=\eta_{0} \exp (D E / k T) .
$$

The activation energy for stress relaxation was estimated to be $310 \mathrm{~kJ} / \mathrm{mole}$. This value is much larger than the value of $190 \mathrm{~kJ} / \mathrm{mole}$ for non-IAD $\mathrm{PbTiO}_{3}$ films.

Figure 14 depicts the effects of grain and mean grain size on film stress. Several points were selected from the stresstime plot [Fig. 14(a)] and the corresponding microstructures were examined. It was found that stress relaxation in the $\mathrm{PbTiO}_{3}$ film was dominated by two mechanisms: ${ }^{13}$ the rotation of the misorientation of the small grains or subcell microstructure, and grain growth. The former mechanism could account for the change of the $I_{100}: I_{001}$ ratio associated with film stress levels [Fig. 14(b)] while the latter mechanism could have contributed to the reduction in the stress levels [Fig. 14(c)]. However, the average grain size was found to be smaller than that of non-IAD films. Occasionally some single-grain hillock formation was found in the films. The number density of hillocks in the IAD films was found to be significantly lower than that in non-IAD films.

From the aforementioned results, it is clear that the stress relaxation in IAD films also obeyed the viscous flow model, and the dominant mechanism associated with stress relax-

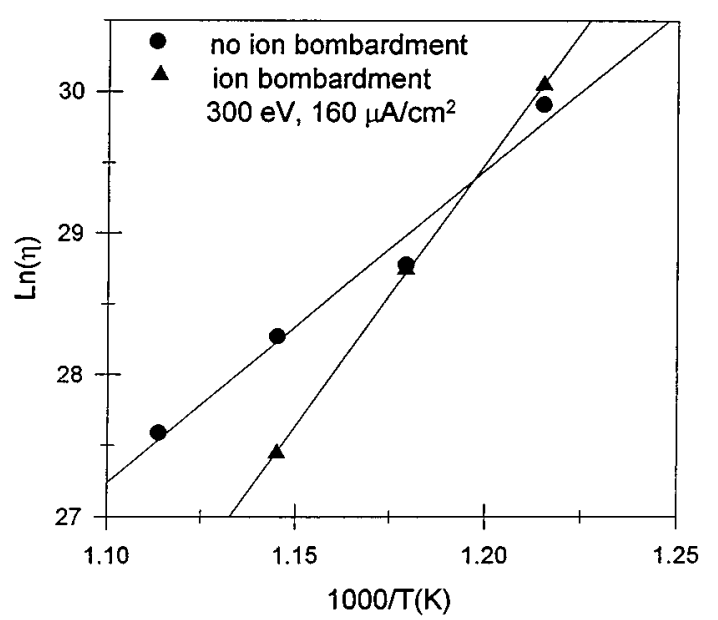

FIG. 13. Arrhenius behavior of the viscosity of $\mathrm{PbTiO}_{3}$ thin films. 


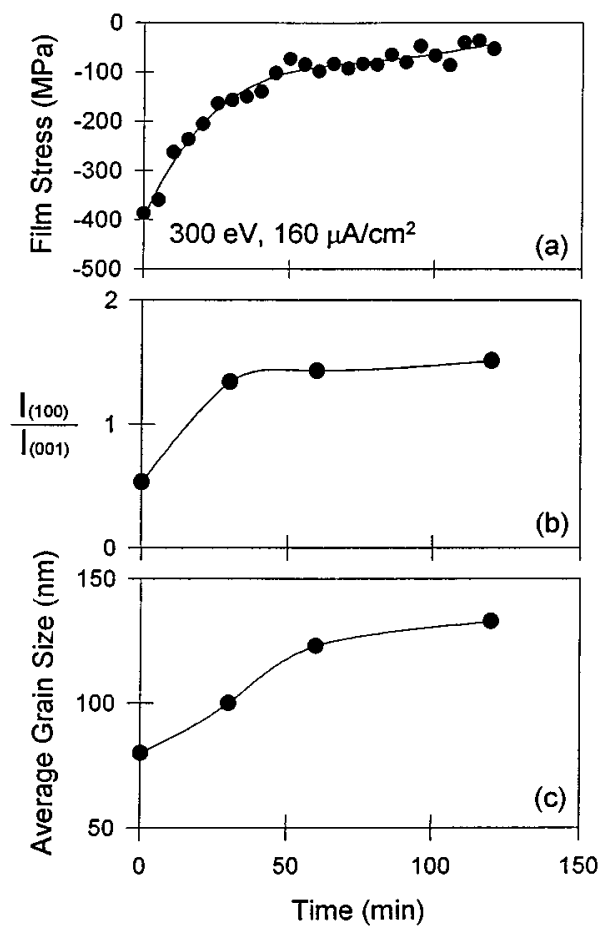

FIG. 14. Effects of both orientation and grain size on film stress. (a) Film stress as a function of annealing time, (b) change in orientation, and (c) changes in average grain size with annealing time.

ation was still grain growth. The difference in activation energy was converted into the stress difference in the film before and after relaxation. The difference was $160 \mathrm{MPa}$ which is reasonably close to the experimental value. Therefore, it may be concluded that energetical ion bombardment can result in the reduction in film stress. Accordingly, the rate of stress relaxation can also be decreased.

Figure 15 depicts the effect of ion bombardment on stress relaxation. Although the stress levels in the $\mathrm{PbTiO}_{3}$ films were different for different ion flux densities (at a constant

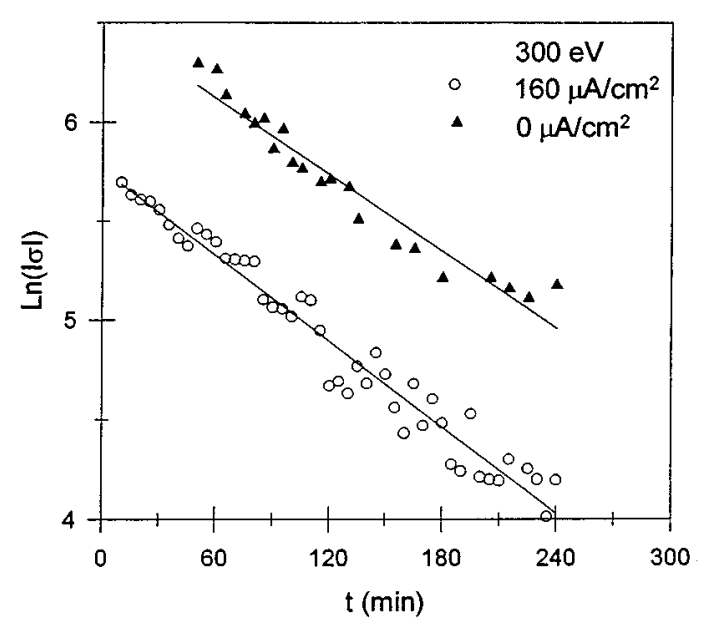

FIG. 15. Effect of ion flux density on stress relaxation behavior.
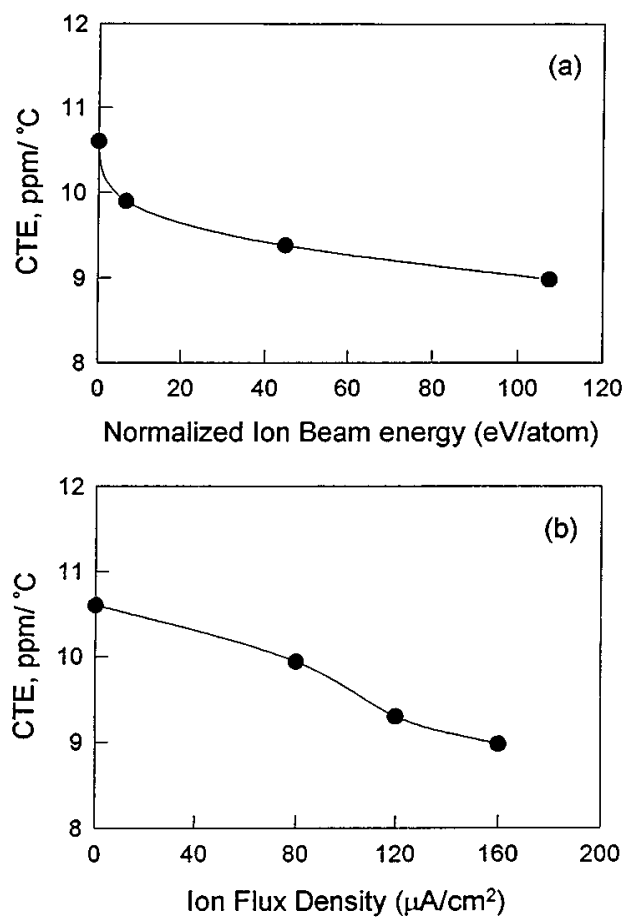

FIG. 16. CTE as a function of (a) normalized ion beam energy and (b) ion flux density.

ion beam energy), the stress relaxation behavior was not affected by increasing ion flux density.

\section{Structure-property-processing interrelationships}

The cooling portion of the stress-temperature plot in Fig. 5 depicts the development of thermal stress $\left(\sigma_{\text {th }}\right)$ in the films, and it also shows very good linearity. Thermal stress generated during cooling was obtained from the slope of the curve, defined as

$$
\text { slope }=d \sigma_{\text {th }} / d T=\left[E_{f} /\left(1-\nu_{f}\right)\right]\left(\alpha_{s}-\alpha_{f}\right),
$$

where $E_{f} /\left(1-\nu_{f}\right)$ is the biaxial modulus of the film and $\left(\alpha_{s}-\alpha_{f}\right)$ is the difference in the coefficient of thermal expansion (CTE) between the substrate and the film. The CTE of the film, $\alpha_{f}$, was readily obtained by assuming that the biaxial modulus of the films was constant.

Figures 16(a) and 16(b) shows the change of the CTE as functions of normalized ion beam energy, eV/atom and ion flux density at $300 \mathrm{eV}$ ion beam energy, respectively. The CTE of thin $\mathrm{PbTiO}_{3}$ films was found to decrease with both increasing normalized ion beam energy and ion flux density (at $300 \mathrm{eV}$ ). The values were also found to approach those of the bulk polycrystalline $\mathrm{PbTiO}_{3}$ ceramics. ${ }^{24}$ The reduction in the value of the CTE was attributed to morphological changes in the grain size. For instance, the mean grain size was $\sim 0.2 \mathrm{~mm}$ for non-IAD films ${ }^{12,13}$ and $0.1 \mathrm{~mm}$ for the IAD film deposited at $300 \mathrm{eV}$ and $160 \mu \mathrm{A} / \mathrm{cm}^{2}$ shown in Fig. 14. Similar behavior has also been found in ion bombarded copper films. ${ }^{16}$

Figure 17(a) shows the change in film stress as a function of grain size. Compressive film stress decreased with in- 

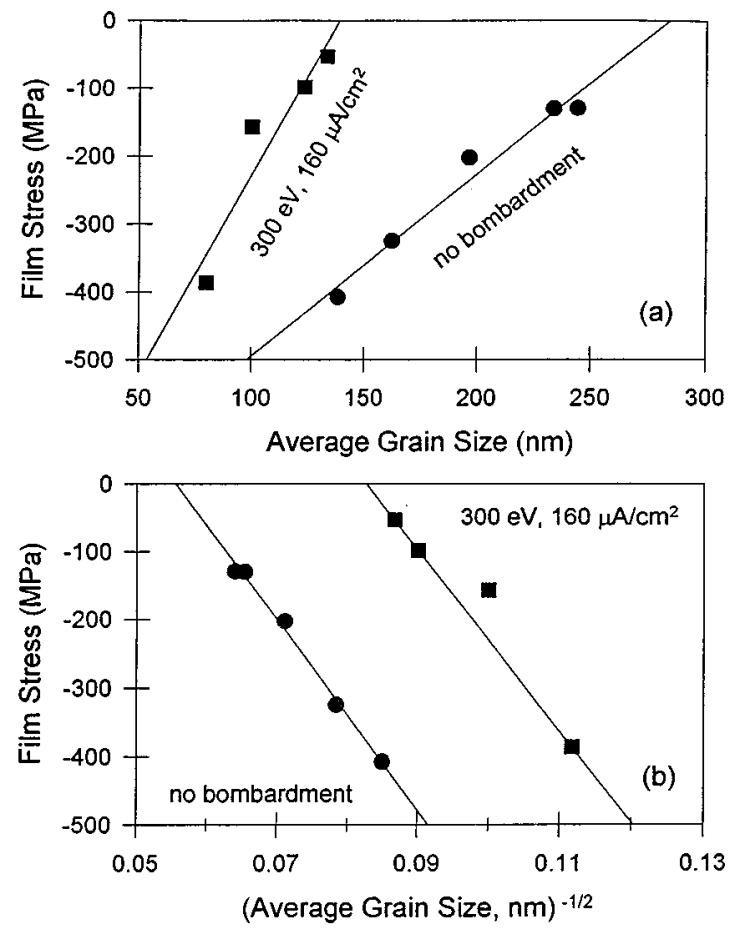

Fig. 17. Film stress as a function of (a) average grain size, $d$, and (b) $d^{-1 / 2}$.

creasing grain size. In our previous work, we found grain growth to be the major mechanism responsible for stress relaxation in non-IAD $\mathrm{PbTiO}_{3}$ thin films. ${ }^{13}$ Similar behavior was observed for $\mathrm{IAD} \mathrm{PbTiO}_{3}$ films, except that the grain sizes were smaller.

Thin films with compressive stress often show better mechanical properties such as higher hardness and wear resistance. ${ }^{1}$ To a first approximation, the strength, $S$, of a compressive film can be defined as

$$
S=S_{0}-\sigma,
$$

where $S_{0}$ is the strength of a stress-free film and $\sigma$ is the film stress. The material strength greatly depends on the grain size of the material and often obeys the Hall-Petch relationship ${ }^{25}$

$$
S=S^{\prime}+k d^{-0.5},
$$

where $S^{\prime}$ and $k$ are constants, and $d$ is the grain size. The film strength dependence on the grain size can therefore be given as

$$
\sigma=\sigma_{0}-k d^{-0.5}
$$

Figure 17(b) depicts the film stress as a function of $d^{-0.5}$. The two straight lines were found to be parallel to each other and the slope, $k$, was process independent. This suggests that the mechanism associated with stress relaxation in $\mathrm{PbTiO}_{3}$ thin films did not change due to the different deposition processes, although the grain size of the films was process dependent.

\section{SUMMARY}

For the first time, the effects of low-energy ion bombardment on multicomponent oxide and multilayer systems were studied extensively by the in situ stress measurement technique. The multilayer approach was employed to accurately control the composition of the $\mathrm{PbTiO}_{3}$ films. Individual oxide layers, i.e., lead oxide and titanium oxide, were deposited on sapphire substrates with a concurrent low energy (100$300 \mathrm{eV}) \mathrm{Ar}^{+}$ion irradiation. The effect of ion bombardment on $\mathrm{PbTiO}_{3}$ formation can be summarized as follows.

(1) Film stress of the as-deposited multilayer was tensile and decreased with increasing ion flux density. It was also found that, at lower energies, the initial film stress drastically decreased as the normalized ion beam energy increased; the increase at larger ion energies was smaller. The effect of the ion energy on initial film stress was also successfully modeled.

(2) The bombardment of low-energy ions during film growth was also found to affect the stress behavior of the multilayer during thermal excursions.

(3) The formation of the $\mathrm{PbTiO}_{3}$ phase was accelerated by ion bombardment; the ion bombardment during deposition was believed to significantly increase the available nucleation sites at the interface of the oxide layers and thereby enhance the reaction process.

(4) The mechanism of stress relaxation was not affected by ion bombardment. The higher activation energy associated with stress relaxation for the IAD films, compared to that for non-IAD films, was attributed to the difference in value of the film stress prior to relaxation, and resulting from ion bombardment.

(5) The coefficient of thermal expansion of the $\mathrm{PbTiO}_{3}$ films was modified by ion bombardment. The CTE monotonically approached bulk value when the ion flux density and ion beam energy were increased. It was also found that film stress of the $\mathrm{PbTiO}_{3}$ films greatly depends on their mean grain size. The mean grain size of the $\mathrm{PbTiO}_{3}$ film decreased when the film was bombarded by lowenergy ions during deposition.

${ }^{1}$ G. Carter and D. G. Armour, Thin Solid Films 80, 13 (1981).

${ }^{2}$ F. A. Smidt, Int. Mater. Rev. 35, 61 (1990).

${ }^{3}$ T. C. Huang, G. Lim, F. Parmigiani, and E. Kay, J. Vac. Sci. Technol. A 3, 2161 (1985).

${ }^{4}$ P. Ziemann and E. Kay, J. Vac. Sci. Technol. A 1, 512 (1983).

${ }^{5}$ K. H. Muller, J. Appl. Phys. 59, 2803 (1986).

${ }^{6}$ E. Kay, F. Parmigiani, and W. Parrish, J. Vac. Sci. Technol. A 5, 44 (1987).

${ }^{7}$ M. Drechsler, M. Junack, and R. Meclewski, Surf. Sci. 97, 111 (1980).

${ }^{8}$ E. Krikorian and R. J. Sneed, Astrophys. Space Sci. 65, 129 (1979).

${ }^{9}$ J. M. E. Harper and R. J. Gambino, J. Vac. Sci. Technol. 16, 1901 (1979).

${ }^{10}$ F. M. d'Heurle and J. M. E. Harper, Thin Solid Films 171, 81 (1989).

${ }^{11}$ C. C. Li and S. B. Desu, Ceramic Transactions, Vol. 25: Ferroelectric Films, edited by A. Bhalla and K. M. Nair (The American Ceramic Society, Columbus, OH, 1992), pp. 59-71.

${ }^{12}$ C. C. Li and S. B. Desu, J. Vac. Sci. Technol. A 14, 1 (1996).

${ }^{13}$ C. C. Li and S. B. Desu, J. Vac. Sci. Technol. A 14, 7 (1996). 
${ }^{14}$ O. Knotek, R. Elsing, G. Kramer, and F. Jungblut, Surf. Coat. Technol. 46, 265 (1991).

${ }^{15}$ D. S. Yee, J. Floro, D. J. Mikalsen, J. J. Cuomo, K. Y. Ahn, and D. A. Smith, J. Vac. Sci. Technol. A 3, 2121 (1985).

${ }^{16}$ R. A. Roy, J. J. Cuomo, and D. S. Yee, J. Vac. Sci. Technol. A 6, 1621 (1988).

${ }^{17}$ C. A. Davis, Thin Solid Films 226, 30 (1993).

${ }^{18}$ D. R. McKenzie, D. A. Muller, and B. A. Pailthorpe, Phys. Rev. Lett. 67, 773 (1991).

${ }^{19}$ R. A. Roy, R. Petkie, and A. Boulding, J. Mater. Res. 6, 80 (1991).
${ }^{20}$ P. J. Martin, Vacuum 36, 585 (1986).

${ }^{21}$ M. Marinov, Thin Solid Films 46, 267 (1977).

${ }^{22} \mathrm{~J}$. Baglin, Handbook of Ion Beam Processing Technology, edited by J. J. Cuomo, S. M. Rossnagel, and H. R. Kaufman (Noyes, Park Ridge, NJ, 1989), p. 279.

${ }^{23}$ S. Ikegami, I. Ueda, and T. Nagata, J. Acoust. Soc. Am. 50, 1060 (1971). ${ }^{24}$ G. Shirane and S. Hoshino, J. Phys. Soc. Jpn. 6, 265 (1951).

${ }^{25}$ A. G. Guy and J. J. Hren, Elements of Physical Metallurgy, 3rd ed. (Addison-Wesley, Reading, MA, 1974), p. 464. 